\title{
Use of a novel parenchymal clamp for laparoscopic and open partial nephrectomy
}

\author{
Paul Toren, MD; Turki Al-Essawi, MD; Anthony Mclean, MD; Umesh Jain, MD, FRCSC
}

\begin{abstract}
Increasing data advocates the wider use of partial nephrectomy for renal tumours amenable to this approach. We describe the initial North American use of a novel parenchymal clamp in an open and a laparoscopic partial nephrectomy. Initial results in 3 patients (2 open, 1 laparoscopic) demonstrate excellent preservation of renal function and good oncologic outcomes. Hilar dissection was avoided in all cases and the estimated blood loss was low. In our small series, we found this device to be a safe and useful adjunct to partial nephrectomy.
\end{abstract}

Can Urol Assoc J 2010;4(5):E133-136

\section{Introduction}

Partial nephrectomy has been proven to be an equally effective curative treatment for localized renal cell carcinoma less than $4 \mathrm{~cm} .{ }^{1}$ Long-term data suggest improved overall survival with partial nephrectomy compared to radical nephrectomy. ${ }^{2}$

Studies have addressed the technical aspects of partical nephrectomy, particularly the impact of ischemic time on renal function. ${ }^{1,3,4}$ Partial nephrectomy is commonly performed with renal artery occlusion to control bleeding. ${ }^{5}$ Warm ischemic times are ideally kept less than 20 to 30 minutes; use of ice slush to create cold ischemic conditions extends the target time to less than 35 to 55 minutes. ${ }^{3,6}$ The use of manual compression of the kidney without vascular occlusion is also reported in the literature. ${ }^{7}$ While manual compression avoids any potential vascular pedicle injury, its effect on renal function and recovery is not well-studied. 3,6,7 However, this technique may not be done with a laparoscopic partial nephrectomy.

There have been early reports of laparoscopic parenchymal clamping using a Satinsky- or Debakey-style clamp. ${ }^{8-10}$ Alternatively, an adjustable circumferential banding device has been reported exclusively to date in France. ${ }^{11}$ We report the first Canadian use of this new parenchymal clamp for use in laparoscopic and open partial nephrectomies.

\section{Methods}

The parenchymal clamp device has previously been used in France. ${ }^{11}$ Constructed with about $1-\mathrm{cm}$ wide flat nitinol band; the device can be placed through a 10-mm laparoscopic port. The device is sterilizable and can be reused a limited number of times.

Operative technique generally follows standard procedures. Laparoscopic placement of the clamp is usually through a lateral port site to allow minimal interference from the operating port sites. With the parenchymal clamp, the renal hilum is not dissected out and the perirenal fat and renal capsule are dissected further than usual to facilitate placement of the clamp away from the edge of the tumour resection. With the aid of preoperative imaging, the surgeon must position the clamp such that complete excision of the tumour with negative margins may be performed. The clamp is tightened such that the bleeding is adequately controlled once the parenchyma is incised; it is initially tightened similar to the pressure exerted by one's hand, but may be adjusted as needed. Proper placement of the clamp is more important for laparoscopic use, where manual compression may not be used if the clamp should slip. Its application is best suited for polar tumours where there is adequate parenchyma between the tumour and the hilum.

Health Canada approval and institutional approval for use of the device were obtained. A brief live and video demonstration of the device was used to instruct surgeons on its use. Demographics, operative details and perioperative laboratory values were collected from the patients' charts.

\section{Results}

The operative characteristics of the cases with the parenchymal clamp are summarized in Table 1 . The laboratory results are summarized in Table 2, and the pathologic results in Table 3. A summary of each case follows. 


\begin{tabular}{|c|c|c|c|c|c|c|c|}
\hline Patient & Approach & $\begin{array}{l}\text { Preoperative } \\
\text { size of tumour, } \\
\text { cm }\end{array}$ & Side & $\begin{array}{c}\text { Collecting } \\
\text { system entry }\end{array}$ & $\begin{array}{l}\text { Operative time, } \\
\text { min }\end{array}$ & $\begin{array}{c}\text { Clamp time, } \\
\text { min }\end{array}$ & $\begin{array}{l}\text { EBL } \\
\text { (cc) }\end{array}$ \\
\hline 1 & $\begin{array}{l}\text { Transperitoneal } \\
\text { laparoscopic }\end{array}$ & 1.5 & Right & No & 165 & 21 & 150 \\
\hline 2 & Supra-11th flank & 3.5 & Left & No & 133 & 10 & 250 \\
\hline 3 & Supra-11th flank & 4 & Left & Yes & 140 & 17 & 250 \\
\hline
\end{tabular}

$\mathrm{EBL}=$ estimated blood loss.

\section{Case 1}

A 74-year-old male presented with an incidental $1.5-\mathrm{cm}$ exophytic right renal mass. His past medical history is remarkable for an myocardial infarction, previous coronary artery bypass graft and abdominal aortic aneurysm repair. A laparoscopic partial nephrectomy was performed using the parenchymal clamp through a medial $10-\mathrm{mm}$ port site. The vessels were not dissected out. The clamp was applied for 21 minutes. A bolster and hemostatic agents were used to secure hemostasis. There was no collecting system entry and the total estimated blood loss was $<150$ cc. Operative time was 165 minutes. He recovered uneventfully and was discharged 3 days postoperatively.

\section{Case 2}

A 70-year-old female presented with a 3-cm lower pole mass incidentally found on computed tomography imaging. Her past medical history was remarkable for a remotely calcified atrophic right kidney. An open supra-11 flank incision was made and access gained to the left kidney. Hilar dissection

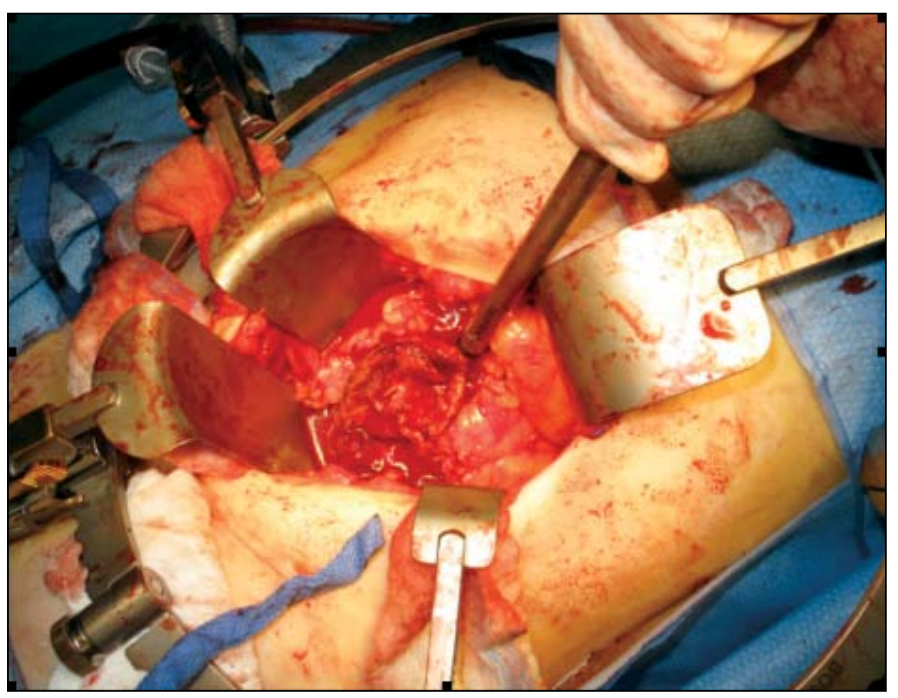

Fig. 1. Intraoperative photograph of the kidney clamp applied with the tumour excised (Case 2). Note the hemostasis and improved exposure without any clamping of the renal vessels. was not performed. The perirenal fat was dissected off the renal capsule to facilitate the placement of our parenchymal clamp. The clamp was applied for 10 minutes as we excised the tumour with a margin of normal tissue (Fig. 1). Bleeding was minimal; a hand was used in place of the clamp to manipulate the kidney as a bolster was sutured in place. Estimated total blood loss was $250 \mathrm{cc}$ and operative time was 133 minutes. The patient recovered uneventfully and was discharged 5 days postoperatively.

\section{Case 3}

A 72-year-old male with a 4-cm incidentally found left upper pole mass was brought to the operating room for an open left partial nephrectomy. Similarly, we used a supra-11 flank incision and mobilized the kidney outside Gerota's fascia. We exposed the renal capsule below the tumour and dissected off the perirenal fat to allow placement of the parenchymal clamp. Hilar dissection was not performed. The clamp was applied as the tumour was excised with a margin of normal parenchyma (Fig. 2). A small entry was made into an upper calyx, which was repaired. Several small bleeders were sutured. A bolster was sutured in place. The total clamp

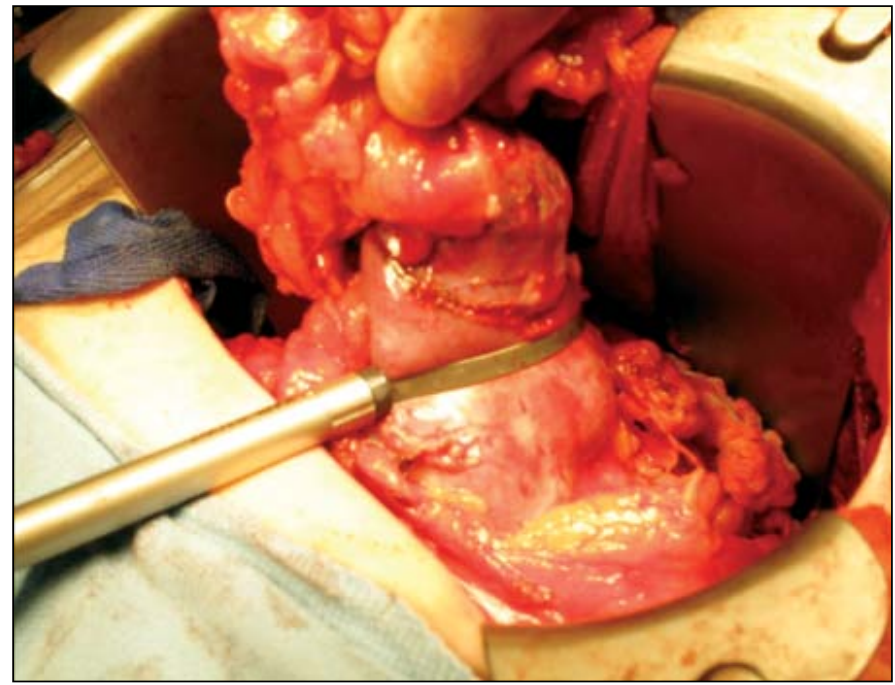

Fig. 2. Intraoperative photograph of clamp applied to kidney with initial incision into parenchyma (Case 3). 
Table 2. Laboratory characteristics following use of parenchymal clamp

\begin{tabular}{lcccccc}
\hline Patient & Preoperative Hgb & POD \#1 Hgb & $\begin{array}{c}\text { Postoperative Hgb } \\
\text { nadir }\end{array}$ & Preoperative Cr & Cr POD \#1 & Postoperative Cr \\
nadir & 123 & 123 & 88 & 123 & 112 \\
\hline 1 & 159 & 114 & 107 & 109 & 121 & 107 \\
\hline 3 & 149 & 125 & 121 & 115 & 124 & 91 \\
\hline *Solitary kidney. Hgb = hemoglobin: $\mathrm{POD}=$ postoperative day; $\mathrm{Cr}=$ creatinine. & & &
\end{tabular}

time was 17 minutes and the total estimated blood loss was $250 \mathrm{cc}$, with an operative time of 140 minutes. The patient recovered uneventfully, but slowly, and was discharged on postoperative day 6 .

\section{Discussion}

Our experience indicates that this device is a useful adjunct to performing partial nephrectomy, in laparoscopic and open cases. This concurs with several recent publications, which have described the use of a parenchymal clamp for laparoscopic partial nephrectomies. ${ }^{10,11}$ This series represents the first published use in North America.

Warm ischemic time is important for the preservation of renal function, with duration of vessel clamping previously found to be an independant predictor of renal insufficiency..$^{12}$ A previous study has shown this to be particularly important in patients with pre-existing renal impairment and elderly patients. ${ }^{4}$ Our results demonstrate excellent shortterm preservation of renal function in elderly patients particularly at risk for renal failure. In particular, one woman with a solitary kidney showed essentially no change in her renal function at time of discharge. Parenchymal clamping, by sparing the rest of the kidney from ischemia, may result in less re-perfusion damage, although this has not been wellstudied. ${ }^{6}$ The use of such an approach is not new, ${ }^{13}$ although perhaps has been overlooked. ${ }^{14}$

Compared with using a Satinsky or similar clamp, this device allows equal compression circumferentially, which we feel is less traumatic. Our initial concern that the device may cut through parenchyma was unfounded once we had used the device. For open procedures, one of the major advantages may be for urologists who perform the procedure with surgical assistants who are not trained in urology. In

Table 3. Pathologic results of cases

\begin{tabular}{lllc}
\hline Patient & \multicolumn{1}{c}{ Pathology } & Margins & $\begin{array}{c}\text { Maximal } \\
\text { dimension, } \mathbf{~ c m}\end{array}$ \\
\hline 1 & $\begin{array}{l}\text { Papillary RCC, } \\
\text { Furhman grade 3/4 }\end{array}$ & Negative & 1.8 \\
\hline 2 & $\begin{array}{l}\text { Clear cell RCC, } \\
\text { Furhman grade } 1 / 4\end{array}$ & Negative & 3.2 \\
\hline 3 & $\begin{array}{l}\text { Clear cell RCC, } \\
\text { Furhman grade 2/4 }\end{array}$ & Negative & 4.0 \\
\hline RCC = renal cell carcinoma. & & \\
\hline
\end{tabular}

such situations, better exposure is obtained, without the aid of an assistant familiar with squeezing the kidney (Fig. 2). Avoiding dissection of the renal hilum can be time-saving, particularly for the laparoscopic approach, where this can be more tedious.

Disadvantages include the cost of the device, although it can be sterilized and reusable for at least 5 times when handled properly. We did note that the band tends to slide into a depression in the contour of the kidney while tightening. This did increase the distance from the margin of the tumour where we applied the device, depending on the renal contour. Once tight, however, it did stay in place. We found placement of the clamp more difficult for the midpole tumour, and felt it is more ideal for polar tumours where less ischemia of normal tissue also occurs. Finally, not having hilar vascular control can be problematic in the event of major hemorrhage. Moreover, this dissection needs to be taught to residents.

Compared to previous published papers in academic centres, ${ }^{8,10,11,15}$ our laparoscopic experience was similar, with negative margins, low blood loss and excellent preservation of renal function. Our literature search could not identify previous published reports of use of this parenchymal clamp in open partial nephrectomy.

Our study is clearly limited by only presenting shortterm results in a very small series, but does show promise warranting further evaluation. Further research needs to be done evaluating the benefit of regional ischemia on renal functional outcomes.

\section{Conclusion}

With increasing evidence advocating for greater use of partial nephrectomy for small renal masses, ${ }^{1,2}$ we found this new clamp to be an effective and useful device for use in laparoscopic and open partial nephrectomy.

Department of Surgery, Division Urology, University of Toronto, St. Joseph's Health Care Centre, Toronto, ON

Competing interests: None declared.

This paper has been peer-reviewed. 
Toren et al.

\section{References}

1. Uzzo RG, Novick AC. Nephron sparing surgery for renal tumors: indications, techniques and outcomes. J Urol 2001;166:6-18.

2. Zini L, Perrotte P, Capitanio U, et al. Radical versus partial nephrectomy: effect on overall and noncancer mortality. Cancer 2009;115:1465-71.

3. Becker F, Van Poppel H, Hakenberg OW, et al. Assessing the impact of ischaemia time during partial nephrectomy. Eur Urol 2009;56:625-34.

4. Desai MM, Gill IS, Ramani AP, et al. The impact of warm ischaemia on renal function after laparoscopic partial nephrectomy. BJU Int 2005;95:377-83.

5. Novick A. Open surgery of the kidney. In: Wein AJ, Kavoussi LR, Novick AC, Partin AJ, Peters CA, editors. Campbell-Walsh Urology, 9th edition. Philadelphia, PA: Saunders Elsevier; 2007:1686-768.

6. Simmons MN, Schreiber MJ, Gill IS. Surgical renal ischemia: a contemporary overview. J Urol 2008; 180:19-30.

7. Ficarra V, Novara G, Secco S, et al. Preoperative Aspects and Dimensions Used for an Anatomical (PADUA) classification of renal tumours in patients who are candidates for nephron-sparing surgery. Eur Urol 2009 Aug 4. [Epub ahead of print].

8. Rodriguez-Covarrubias F, Gabilondo B, Borgen JL, et al. Partial nephrectomy for renal tumors using selective parenchymal clamping. Int Urol Nephrol 2007;39:43-6.
9. Mejean $A$, Vogt $B$, Cazin $S$, et al. Nephron sparing surgery for renal cell carcinoma using selective renal parenchymal clamping. I Urol 2002;167:234-5.

10. Simon J, Bartsch G Jr, Finter F, et al. Laparoscopic partial nephrectomy with selective control of the renal parenchyma: initial experience with a novel laparoscopic clamp. BJU Int 2009; 103:805-8.

11. Khedis $M$, Bellec L, Leobon $B$, et al. Partial nephrectomy by selective renal parenchymal clamping using a new clamp. Prog Urol 2007;17:41-4.

12. Jeldres $C$, Bensalah $\mathrm{K}$, Capitanio $\mathrm{U}$, et al. Baseline renal function, ischaemia time and blood loss predict the rate of renal failure after partial nephrectomy. BJU Int 2009;103:1632-5.

13. Storm FK, Kaufman JJ, Longmire WP. Kidney resection clamp: new instrument. Urology 1975;6:494-5.

14. Janetschek G. Laparoscopic partial nephrectomy for RCC: How can we avoid ischemic damage of the renal parenchyma? Eur Urol 2007;52:1303-5.

15. Verhoest $\mathrm{G}$, Manunta A, Bensalah $\mathrm{K}$, et al. Laparoscopic partial nephrectomy with clamping of the renal parenchyma: initial experience. Eur Urol 2007;52:1340-6.

Correspondence: Dr. Umesh Jain, St. Joseph Health Centre, 30 The Queensway, Toronto, ON M6R 1B5; jainu@stijo.on.ca 